\title{
Effects of Leisure-Time Physical Activity and Exercise on Pain and Health-Related Quality of Life in Older Females with Arthritis
}

\author{
Barbara Piasecka, Wally J Bartfay*, Emma Bartfay and Mika Nonoyama \\ Associate Professor and Director BAHSc, Faculty of Health Sciences, Canada
}

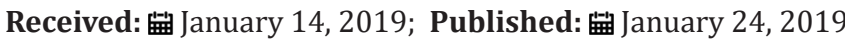

*Corresponding author: Wally J Bartfay, Associate Professor and Director BAHSc and BHSc Programs, Faculty of Health Sciences, UA 3022, 2000 Simcoe Street North, Oshawa, Ontario, Canada

Abstract

Objective: Arthritis is a chronic, degenerative disease that affects two million Canadians, of which the majority are older females (65+ years). The associated symptom of pain can negatively affect health-related quality of life (HRQoL). Living an active lifestyle through leisure-time physical activity (LTPA) and exercise may have health benefits. The aim of this cross-sectional study was to evaluate health outcomes in active versus inactive females aged 65 years or older with arthritis. Specifically, do active older females with arthritis have lower levels of joint pain associated with arthritis and higher HRQoL, in comparison to inactive participants?

Methods: 40 older females from the Durham Region of Ontario, Canada participated in the study of which 60\% (N=24) were categorized as active (mean age $=71$ years +6.5$)$ and $40 \%(\mathrm{~N}=16)$ were considered inactive (mean age $=82$ years +8.8$)$. Visual analog scale (VAS), Medical Outcomes Short Form-12 (SF-12) and Activity Levels Questionnaire for Older Adults (ALQOA) were employed. RESULTS: Active older arthritic females reported significantly lower pain $(\mathrm{p}<0.0001)$ and higher HRQoL $(\mathrm{p}<0.0001)$, in comparison to their inactive counterparts. Moreover, active older females reported significantly higher Physical and Mental Composite Scores (PCS and MCS) ( $<<0.0001$ and $p=0.05$, respectively), in comparison to inactive counterparts.

Conclusion: These findings suggest that older females with arthritis who are active report significantly lower pain and higher HRQoL levels.

Keywords: Older Adults; Arthritis; Health-Related Quality of Life; Pain; Leisure-Time Physical Activity; Exercise

Abbreviations: ALQOA: Activity Levels Questionnaire for Older Adults; CCHS: Canadian Community Health Survey; HRQoL: Health-Related Quality of Life; Kkds: Kilocalories Per kilogram; LTPA: Leisure-Time Physical Activity; LTPAEE: Leisure-Time Physical Activity Energy Expenditure; MCS: Mental Composite Score; MET: Metabolic Energy; MI: Moderate Intensity; OA: Osteoarthritis; PA: Physical Activity; PCS: Physical Composite Score; RA: Rheumatoid Arthritis; REB: Research Ethics Board; SD: Standard Deviation; SF-12: Medical Outcomes Short Form-12; VAS: Visual Analog Scale

\section{Introduction}

Arthritis is regarded as one of the most debilitating chronic health conditions globally, and there is no known cure for its many forms. As the population ages and life expectancies increase, the prevalence of arthritis is expected to increase worldwide, especially amongst older females [1]. In Canada, two million (44\%) older adults aged 65+ currently live with arthritis, [2] and one-intwo (50\%) affected are females [3]. Arthritis rates have steadily increased and will continue increasing in the decades to come [4]. In fact, these numbers are predicted to increase by one percent every five years, virtually doubling by 2031 . Hence, the growing incidence and management of arthritis is a growing public health concern in Canada and globally. Evidence suggests that persons living with arthritis generally have poor physical health outcomes and are more likely to report decreased health-related quality of life (HRQoL) and mental health [5]. Exercise and/or physical activity (PA) have been shown to improve and/or maintain physical and mental health [67]. Indeed, exercise and PA may provide a cost effective and safe non-pharmaceutical alternative for the management of patients with arthritis by allied health professionals.

Currently, there is no "gold standard" to directly and/or indirectly measure PA and/or exercise levels [8]. Nonetheless, total average daily energy expenditure for specific leisure-time activities is a method widely employed for assessing self-reported activity levels in Canadians, including older adults [9-10]. According to 
the Canadian Community Health Survey (CCHS), 43\% of older Canadians aged 65+ were classified as moderately active or active based on leisure time scores [10-11]. Nonetheless, little is currently known about the health benefits of leisure PA and exercise on health outcomes in older Canadian females with arthritis. Accordingly, the aim of the present study was to compare leisure-time PA and exercise between active versus inactive older Canadian females with arthritis, and their effects on pain and HRQoL outcomes.

\section{Materials and Methods}

A cross-sectional study using non-probability convenience sampling was employed to evaluate the association between pain and health-related quality of life (HRQoL) scores with PA levels in active versus inactive older females with arthritis. A total of 40 older females aged 65+ with arthritis from the Durham Region, Ontario, Canada participated in this study. Key dependent variables assessed included pain intensity; HRQoL scores, and PA levels. Pain and HRQoL were measured by a self-reported visual analog scale (VAS), and the Medical Outcomes Short Form-12 (SF-12) scale. HRQoL was assessed via a VAS index comprised of a five-point scale; where values ranged from 0 (very poor) to 4 (excellent). HRQoL was also measured by using the SF-12. This self-administered questionnaire is comprised of 12 questions which provides targeted information on general health; emotional limitations; pain; physical function limitations, and overall social and mental health. The pain domain of the SF-12 was used to evaluate pain scores on a five-point scale ranging from 1 (not at all) to 5 (extremely painful) [12].

The SF-12 has been previously reported to be a highly reliable and valid questionnaire $[13,14]$. Moreover, this instrument has also been previously shown to be reliable and valid for assessing both physical (PCS) and mental component scores (MCS), respectively. The survey's MCS-12 and PCS-12 scores measure the lowest (0) and highest (100) levels of physical and mental health using the questionnaire scores to report HRQoL. Quality Metric's ${ }^{\mathrm{TM}}$ recommended Medical Outcomes Study SAS software program was used to calculate the two PCS and MCS summary scores [15]. In addition, normative data of PCS $(50.5+15.3)$ and MCS $(51.7+$ 9.1) averages for the Canadian population from the SF-12 were employed for comparative purposes. [15] The VAS index was also utilized to measure the strength, magnitude or intensity of pain, with scores ranging from 0 (no pain) to 4 (excruciating) [16]. PA levels were assessed by the Activity Levels Questionnaire for Older Adults (ALQOA) and was created by the study team. Specifically, the scale consists of 21 questions that assessed specific leisuretime physical activity (LTPA) and/or exercise levels in duration (in minutes); the number of times (in days), and intensity levels (light, moderate or vigorous) for older females in an average week in this study. Activities were adapted from the Canadian Community Health Survey (CCHS) [8,11].

Test-retest reliability is a measure of reliability obtained by administering the same instrument twice over a period of time to a group of individuals. The scores from Time 1 and Time 2 are correlated in order to evaluate the instrument for stability over time. The ALQOA was found to have high internal reliability as determined via test-retesting (Chronbach's alpha $=0.97$ ) conducted two weeks apart on 20 test subjects and is deemed a suitable method to measure stable outcomes (e.g., PA levels) that do not necessarily fluctuate constantly [17]. These scores obtained on the ALQOA were subsequently inputted into the leisure-time PA energy expenditure (LTPAEE) index. This assessed the total daily average energy expenditure of total burned calories or energy used (in kilocalories per kilogram [kkds] of body weight for each nonwork activity. Activity levels were determined using pre-assigned metabolic equivalents (METs) for each non-work activity [9], in accordance with the 2011 Compendium of Physical Activities for each subject [18]. Specifically, LTPAEE was calculated using the following equation

$$
\operatorname{LTPAEE}(k k d)=\Sigma\left[\left(N_{i} x D_{i} x M E T_{i}\right) / 7\right]
$$

Where $\mathrm{Ni}$ is the frequency of activity over a week (in days); Di is the duration of activity (in hours), and METi is a constant value for metabolic energy costs of activity (in kilocalories per kilogram of body weight per hour). [9] Based on the calculated LTPAEE, participants were categorized as being inactive (using $<1.5 \mathrm{kkd}$ of body weight per day) or active (using $>1.5 \mathrm{kkd}$ of body weight per day) [9]. Demographic information was also collected (e.g. age, ethnicity, marital status, education level) for all subjects. All selfreported questionnaires were completed by pen-paper method during on-site visits to the six community senior centres and retirement residences within the Durham Region of Ontario, Canada. Written informed consent was obtained from all participants in this study. Moreover, ethical approval was obtained from the University of Ontario Institute of Technology (UOIT) Research Ethics Board (REB), in accordance with Tri-Council standards. All statistical analyses were conducted by SPSS ${ }^{\mathrm{TM}}$ version 21 and Microsoft Excel тм 2011. Descriptive statistics (e.g., mean, SD, ranges, \%'s) were calculated for demographic and outcome variables. Differences between means between active versus inactive were assessed via Student two sample t-tests. The chi-square test was used to examine relationships between categorical variables [19]. A significance level of $\mathrm{P}<0.05$ was deemed significant a priori.

\section{Results}

Demographic characteristics of active and inactive study participants is outlined in Table 1. The study sample was comprised of 40 older arthritic females total, of which 24 were considered active females $(60 \%)$ and 16 were considered inactive females $(40 \%)$. The mean + SD age was $71+6.5$ years for the active group and $82+8.8$ years for the inactive group, respectively. Moreover, most subjects were white ( $96 \%$ active and $100 \%$ inactive); had been previously diagnosed with osteoarthritis (OA) (83\% active and $75 \%$ inactive) and had a family history of arthritis (75\% active and $50 \%$ inactive), respectively. Student two sample t-tests revealed a significant difference in age $(\mathrm{p}<0.001)$, with inactive females being on average 11 years older than the active females. Interestingly, active older females were diagnosed with arthritis at a younger age, in comparison to inactive older females. Of the active sample, the mean age of diagnosis was 53 years old ( $S D=15.1)$. In the inactive group, the mean age of an arthritis diagnosis was 66 years old $(\mathrm{SD}=$ 
10.7, $\mathrm{p}<0.01)$. The chi-square test showed a significant difference regarding marital status $(\mathrm{p}<0.05)$. Specifically, active arthritic older females were more likely to be married, in comparison to their inactive counterparts.

Table 1: Demographic characteristics of the active and inactive groups.

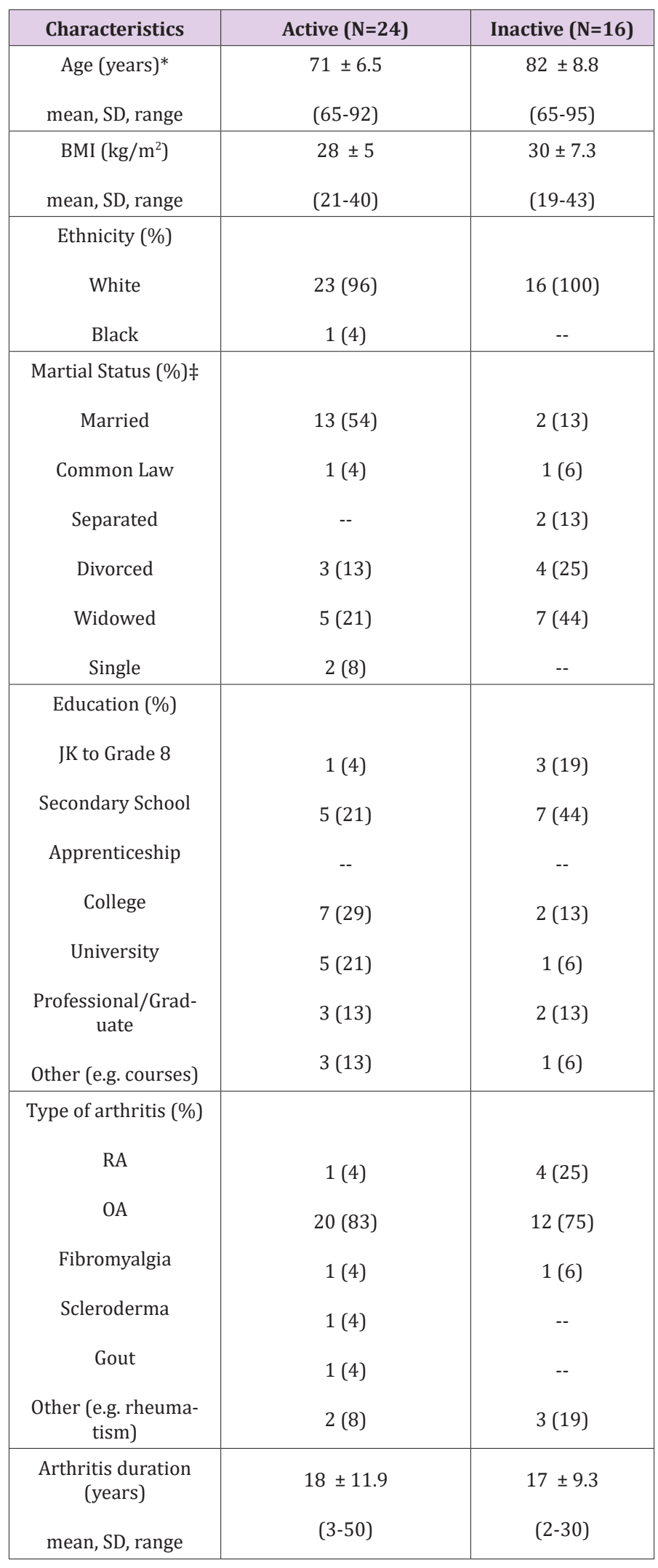

\begin{tabular}{|c|c|c|}
\hline $\begin{array}{c}\text { Age of Dx (years) } \dagger \\
\text { mean, SD, range }\end{array}$ & $52 \pm 15.1$ & $66 \pm 10.7$ \\
\hline $\begin{array}{c}\text { Arthritis family histo- } \\
\text { ry (\%) }\end{array}$ & $(17-75)$ & $(47-87)$ \\
Yes & $18(75)$ & $8(50)$ \\
No & $5(21)$ & $4(25)$ \\
I don't know & $1(4)$ & $4(25)$ \\
\hline
\end{tabular}

Note: ${ }^{*}=\mathrm{p}<0.001 ; \dagger=\mathrm{p}<0.01, \ddagger=\mathrm{p}<0.05$. Abbreviations: $\mathrm{Dx}=$ diagnosis; $\mathrm{JK}=$ junior kindergarten; $\mathrm{OA}=$ osteoarthritis; $\mathrm{RA}=$ rheumatoid arthritis; $\mathrm{SD}=$ standard deviation.

In the active arthritis sample, $54.2 \%$ reported being married and $4.2 \%$ reported being common law; $12.5 \%$ reported being divorced; $20.8 \%$ reported being widowed, and $8.3 \%$ reported being single. In the inactive sample, $12.5 \%$ reported being married and $6.3 \%$ reported being common law; $12.5 \%$ reported being separated; $25 \%$ reported being divorced, $43.8 \%$ were widows and none reported being single. In addition, a significant difference was found in regard to family history of arthritis $(p<0.05)$, where active older females were more likely to have reported a family history of arthritis, in comparison to inactive older females. For the sample of arthritis and active, 75\% reported an arthritis family history, $20.8 \%$ did not and $4.2 \%$ did not know. For the sample of arthritis and inactive, $50 \%$ reported a family history of arthritis, $25 \%$ did not and $25 \%$ did not know. There were no statistically significant differences observed in terms of body mass index (BMI), ethnicity, education, the clinical type of arthritis and/or arthritis duration since diagnosis (in years).

\section{Activity Levels}

Specific leisure PA levels between active and inactive groups are shown in Table 2, which outlines the average total kilocalories per kilogram of body weight (kkds) burned per day in specific leisure-time physical activities and exercises in accordance with the Leisure-Time Physical Activity Energy Expenditure (LTPAEE) formula. [9] Results from a two sample Student t-test showed a significant difference in total kkds per week between active versus inactive groups $(\mathrm{p}<0.0001)$. In total, active arthritic older females reported higher kkds averages from these leisure activities (4.63 $+2.61)$, in comparison to inactive counterparts $(0.73+0.55)$. No significant differences were observed between active versus inactive older females with arthritis in regard to gardening, walking for fun, resistance training or stretching kkds.

Table 2: Activity kilocalories per kilogram of body weight (kkds) per week of active versus inactive groups, 65 years and older females, in Durham Region of Ontario, Canada.

\begin{tabular}{|c|c|c|}
\hline Activities (in kkds) & Active $\mathbf{( N = 2 4 )}$ & Inactive $\mathbf{( N = 1 6 )}$ \\
\hline Gardening & $0.7 \pm 0.6$ & $0.4 \pm 0.2$ \\
\hline Yard work & $0.7 \pm 0.6$ & -- \\
\hline Walk for fun & $0.7 \pm 0.5$ & $0.8 \pm 0.2$ \\
\hline Walking for exercise & $1.4 \pm 1.1$ & 1.0 \\
\hline $\begin{array}{c}\text { Bowling/lawn } \\
\text { bowling }\end{array}$ & $1.4 \pm 1.0$ & -- \\
\hline
\end{tabular}




\begin{tabular}{|c|c|c|}
\hline Golfing & 1.4 & -- \\
\hline Dancing & $1.1 \pm 0.9$ & -- \\
\hline Bicycling & $1.7 \pm 0.3$ & -- \\
\hline Swimming for fun & $1.8 \pm 1.2$ & -- \\
\hline Lane/lap swimming & $2.1 \pm 2.1$ & -- \\
\hline Jogging & 1.3 & -- \\
\hline Calisthenics & $0.8 \pm 0.3$ & -- \\
\hline Resistance training & $0.7 \pm 0.4$ & $0.6 \pm 0.2$ \\
\hline Stretching & $0.4 \pm 0.5$ & $0.5 \pm 0.3$ \\
\hline Yoga & $0.8 \pm 0.5$ & -- \\
\hline Tai Chi & $0.2 \pm 0$ & 0.4 \\
\hline Water Aerobics & $1.2 \pm 0.6$ & -- \\
\hline \multicolumn{3}{|l|}{ Other: } \\
\hline $\begin{array}{c}\text { Softball } \\
\text { Home exercise }\end{array}$ & 1.1 & -- \\
\hline Leg lifts & 0.2 & 0.6 \\
\hline Treadmill & 0.5 & -- \\
\hline Exercise classes & & \\
\hline Curves circuit & 0.6 & -- \\
\hline Stretch + Sculpt & $0.5 \pm 0$ & -- \\
\hline Zumba & $0.6 \pm 0$ & -- \\
\hline $\begin{array}{c}\text { Total activity (per } \\
\text { week) } \pm\end{array}$ & $4.6 \pm 2.6$ & $0.7 \pm 0.6$ \\
\hline
\end{tabular}

Note: ${ }^{*}=\mathrm{p}<0.0001$.Abbreviations: kilocalories per kilogram of body weight (kkds).

\section{Health-related quality of life (HRQoL)}

Table 3 shows the results from the VAS HRQoL scores between the two comparison groups. Notably, active arthritic older females reported higher VAS scores $(2.7+0.6)$, in comparison to inactive females $(1.6+0.6)(p<0.0001)$. Student two-sample t-test revealed statistically significant differences between active versus inactive groups for all eight domains of the HRQoL SF-12 questionnaire. Specifically, active arthritic older females reported higher scores, in comparison to inactive females, for the following domains: (i) General health $(\mathrm{p}<0.001)$; (ii) physical function $(\mathrm{p}<0.0001)$; (iii) role physical $(p<0.0001)$; (iv) role emotional $(p<0.05)$; (v) mental health ( $\mathrm{p}<0.01)$; (vi) vitality $(\mathrm{p}<0.0001)$, and (vii) social functioning $(p<0.01)$, in comparison to their inactive counterparts, respectively. SF-12 findings for bodily pain scores were also employed to examine how pain levels interfered with normal work activities (i.e. work outside the home and housework) during the past reported week, with values ranging from "not at all" to "extremely".

These findings showed that active arthritic older females were more likely to report lower pain outcomes, when compared to their

inactive counterparts $(\mathrm{p}<0.0001)$ (Table 3$)$. Table 4 shows SF-12 physical composite scores (PCS) and mental composite score (MCS) between active versus inactive older females, which were found to be significantly higher in the active females, when compared to inactive females $(\mathrm{p}<0.0001$ and $\mathrm{p}=0.05)$, respectively. Active older females reported a PCS average of $48+7.8$ and an average MCS of 54 +7.3 , in comparison to their inactive counterparts PCS of $30+7.8$ and MCS of $48+11.5$. PCS and MCS were subsequently compared to the mean difference scores obtained to determine the proportion of individuals who are below or above average. Typically, for older adults aged 65+ years, the MCS average is higher than the PCS average [15]. Interestingly, the findings revealed that $63 \%$ of active arthritic older females reported an above average PCS-12 score, in comparison to only $38 \%$ of their inactive counterparts.

Table 3: Results of VAS and SF-12 HRQoL scores between active versus inactive groups, 65 years and older females, in Durham Region of Ontario, Canada.

\begin{tabular}{|c|c|c|}
\hline HRQoL Outcomes & Active $(\mathrm{N}=24)$ & Inactive $(\mathrm{N}=16)$ \\
\hline $\begin{array}{l}\text { VAS HRQoL* } \\
\text { mean, SD } \\
\text { median (range) }\end{array}$ & $\begin{array}{c}2.7 \pm 0.6 \\
3(1-4)\end{array}$ & $\begin{array}{c}1.6 \pm 0.6 \\
2(0-2)\end{array}$ \\
\hline $\begin{array}{l}\text { SF-12 General Health } \dagger \\
\text { mean, SD } \\
\text { (range) }\end{array}$ & $\begin{array}{c}72.7 \pm 16.7 \\
(25-100)\end{array}$ & $\begin{array}{c}45.3 \pm 24.9 \\
(0-85)\end{array}$ \\
\hline $\begin{array}{l}\text { SF-12 Physical Function* } \\
\text { mean, SD } \\
\text { (range) }\end{array}$ & $\begin{array}{l}66.7 \pm 27.3 \\
(25-100)\end{array}$ & $\begin{array}{c}12.5 \pm \_22.4 \\
(0-75)\end{array}$ \\
\hline $\begin{array}{l}\text { SF-12 Role Physical* } \\
\text { mean, SD } \\
\text { (range) }\end{array}$ & $\begin{array}{l}78.6 \pm 21.3 \\
(37.5-100)\end{array}$ & $\begin{array}{c}23.4 \pm 22.3 \\
(0-62.5)\end{array}$ \\
\hline $\begin{array}{l}\text { SF-12 Role Emotional§ } \\
\text { mean, SD } \\
\text { (range) }\end{array}$ & $\begin{array}{c}87.5 \pm 18.4 \\
(50-100)\end{array}$ & $\begin{array}{c}64.8 \pm 34.8 \\
(0-100)\end{array}$ \\
\hline $\begin{array}{l}\text { SF-12 Bodily Pain* } \\
\text { mean, SD } \\
\text { (range) }\end{array}$ & $\begin{array}{c}71.9 \pm 27.9 \\
(0-100)\end{array}$ & $\begin{array}{c}31.3 \pm 28.1 \\
(0-100)\end{array}$ \\
\hline $\begin{array}{l}\text { SF-12 Mental Health } \neq \\
\text { mean, SD } \\
\text { (range) }\end{array}$ & $\begin{array}{c}77.1 \pm 18.8 \\
(50-100)\end{array}$ & $\begin{array}{l}57 \pm 24.6 \\
(25-100)\end{array}$ \\
\hline $\begin{array}{l}\text { SF-12 Vitality* } \\
\text { mean, SD } \\
\text { (range) }\end{array}$ & $\begin{array}{c}67.7 \pm 21.5 \\
(25-100)\end{array}$ & $\begin{array}{c}32.8 \pm 21.8 \\
(0-75)\end{array}$ \\
\hline $\begin{array}{l}\text { SF-12 Social Functioning } \neq \\
\text { mean, SD } \\
\text { (range) }\end{array}$ & $\begin{array}{c}88.5 \pm 16.5 \\
(50-100)\end{array}$ & $\begin{array}{c}60.9 \pm 35.3 \\
(0-100)\end{array}$ \\
\hline
\end{tabular}


Table 4: Results of SF-12 PCS and MCS scores between active versus inactive groups, 65 years and older females, in Durham Region of Ontario, Canada.

\begin{tabular}{|c|c|c|}
\hline Health Composite Scores & Active (N=24) & Inactive $\mathbf{( N = 1 6 )}$ \\
\hline PCS-12* & & \\
mean, SD & $47.7 \pm 7.8$ & $30.1 \pm 7.8$ \\
Above average (\%) & $15(63)$ & $6(38)$ \\
Below average (\%) & $9(38)$ & $10(63)$ \\
\hline MCS-12† & $54.3 \pm 7.4$ & $47.6 \pm 11.5$ \\
mean, SD & $13(54)$ & $8(50)$ \\
Above average (\%) & $11(46)$ & $8(50)$ \\
Below average (\%) & \\
\hline
\end{tabular}

Additionally, 38\% of the active arthritis females reported a below average PCS-12 score, in comparison to $63 \%$ of the inactive females who reported below average PCS-12 scores. The SF12 results also showed that $54 \%$ of the active arthritis females reported above average MCS- 12 scores, in comparison to only $50 \%$ of the inactive females. Findings also revealed that $46 \%$ of active arthritic older females reported below average MCS-12 scores, in comparison to $50 \%$ of their inactive counterparts. Moreover, compared to the mean values of normative data of SF-12 PCS and MCS averages of the Canadian population, this study determined that $45.8 \%$ of the active arthritic older females reported total PCS above the Canadian norms, compared to $0 \%$ of the inactive arthritic older females. In terms of the MCS, this present study found $70.8 \%$ of active arthritic older females reported MCS above the Canadian norms, in comparison to $43.8 \%$ of inactive counterparts.

\section{Pain}

Student two sample t-test findings revealed statistically significant differences in VAS pain and SF-12 pain scores between the two groups. Notably, results showed that active arthritic older females had lower VAS pain scores $(1.3+0.6)$, in comparison to their inactive counterparts $(2.5+0.9)(\mathrm{p}<0.001)$. The results of VAS pain scores are shown in Table 5 for the two groups.

Table 5: Results of VAS pain scores between active versus inactive groups, 65 years and older females, in Durham Region of Ontario, Canada.

\begin{tabular}{|c|c|c|}
\hline Pain Outcomes & Active(N=24) & Inactive(N=16) \\
\hline VAS pain* & $1.3 \pm 0.6$ & $2.5 \pm 0.9$ \\
mean, SD & $1(0-2)$ & $2(1-4)$ \\
median (range) & \\
\hline
\end{tabular}

Note: $*=p<0.001$. Abbreviations: $\mathrm{SD}=$ standard deviation; SF-12= Medical outcomes short form-12; VAS= visual analog scaleb

\section{Discussion}

The aim of this investigation was to examine the effects of leisure-time physical activity (LTPA) and exercise on pain and HRQOL associated with being active versus inactive in older
Canadian females. These preliminary findings suggest that by being active and participating in leisure PA and exercise results in positive physical and mental outcomes in females with arthritis. Notably, these include less reported pain levels and higher health-related quality of life (HRQoL) outcomes. To our knowledge, this is the first study to examine health outcomes associated with total LTPA and/ or exercise levels (e.g. walking, gardening) among older Canadian females with various forms of arthritis. These findings provide preliminary evidence that LTPA may be an effective communitybased health promotion intervention prescribed by allied health professional to their clients. In support of our first hypothesis, active older females reported lower levels of pain, in comparison to inactive females as assessed via a VAS scale and supported by the pain domain of the SF-12. The most prominent PA for active older females in this investigation included gardening; walking for fun; resistance training (e.g. using weights, elastic bands), and stretching.

Similarly, a study that utilized moderate-intensity (MI) PA and/ or exercise interventions reported reduced pain in older adults with knee osteoarthritis (OA) [20]. The results of our study are also in agreement with two reviews that reported pain modification in adults with rheumatoid arthritis (RA) [21-22]. Other researchers investigated pain outcomes between aerobic (e.g. walking) and strengthening exercises (e.g. using weights) in adults with knee OA. They found those who participated in the strengthening and aerobic exercise group reported decreased pain in the affected joint(s), providing benefits for pain management, in comparison to the control group [23]. An indirect effect between quality of life and pain was also observed [23]. In contrast to our investigation, the aforementioned study consisted of aerobic-types of exercise interventions (e.g., walking, running, swimming and cycling), and were similar to the ones identified by our female subjects. However, our study is novel and unique because we examined various common leisure types of PA and exercise forms and focused on older females with various types of arthritis.

In contrast to our findings, three investigations reported no significant changes in pain levels in subjects with rheumatoid arthritis (RA) or osteoarthritis (OA) with middle-aged adults. Specifically, these investigations included exercise regimens consisting of bicycle training; muscle circuit training; aquatic; land-based (e.g. muscle strengthening, aerobic exercise), and other sports related exercises [24-25]. Another study categorized older adults with knee and/or hip OA into sedentary and active groups and examined the effects of an aquatic exercise programme. In contrast to our findings, no significant changes in pain levels were reported between active versus sedentary subjects [26]. In support of our second hypothesis, active older females reported higher health-related quality of life (HRQoL) levels in comparison to their inactive counterparts, as evidenced by both VAS and SF-12 scores. Our findings are consistent with other studies that reported improved HRQoL in active PA groups compared to inactive groups [27-28]. Specifically, higher HRQoL was associated with decreased pain levels, greater physical function and improved mental health outcomes in active individuals [27]. Whereas, decreased HRQoL 
was associated with increasing age, sex, race, marital status and employment status [28].

The two studies employed adults with various types of arthritis diagnosed. These were also the only studies to similarly categorize subjects as active versus inactive which adhered to US PA guidelines, and which are comparable to Canada's Physical Activity guidelines [27-29]. To our knowledge, our findings are the first to report on older active versus inactive female Canadians with various types of diagnosed arthritis. In terms of the MCS, our study found that active older females reported scores above the Canadian norms, in comparison their inactive counterparts. This indicates that active arthritic older females have better health outcomes in terms of HRQOL. Similarly, it has been reported that active adults with arthritis had fewer related physical and mental unhealthy days when compared in inactive females, based on SF-36 scores [27]. Since this study was cross-sectional in design, it was deemed cost and time-effective. Moreover, no risk to follow-up was noted as data was simultaneously collected at a single point in time.

To our knowledge, this is the first Canadian study to propose preliminary research on leisure-time physical activity (LTPA) and exercise levels and arthritis-related health outcomes. However, there are limitations to this study design. It prevented us from determining causality and/or temporal ordering of relationships. We also acknowledge the limitations of our sample size and the employment of a non-random convenience sample, which may increase the change of having a potentially non-representative sample [30]. In addition, self-reported questionnaires were used in this study, which may affect response or recall bias. Therefore, our findings are to be regarded as preliminary in nature and cannot be generalized to all older females aged 65 and older with arthritis. They should also be interpreted with caution. Hence, further large scale prospective and intervention-based studies are warranted to examine the health outcomes associated with leisure PA and exercise in older Canadian females diagnosed with arthritis.

\section{Conclusion}

The growing incidence and management of arthritis is a growing public health concern in Canada and abroad, especially given aging population trends. Indeed, $44 \%(\mathrm{~N}=2$ million) of Canadians older adults over 65 years of age are currently living with arthritis [3,4]. Taken together, our results suggest that living an active lifestyle through higher leisure-time physical activity (LTPA) and/or exercise is related to lower pain and higher HRQoL in older females with arthritis. LTPA and exercise may provide a cost effective, safe and non-pharmaceutical management of arthritis by allied health professionals. Get moving Canada!

\section{Acknowledgment}

I would like to thank my research supervisor; Dr. Wally Bartfay, my supervisory committee; Dr. Emma Bartfay and Dr. Mika Nonoyama, along with my external examiner Dr. Al Salmoni, all of which this would not be possible.

\section{References}

1. (2013) Arthritis in Canada. Toronto (ON), Arthritis Community Research Evaluation Unit (ACREU).

2. Bombardier C, Hawker G, Mosher D (2011) Impact of arthritis in Canada: Today and over the next 30 years. Toronto (ON), Arthritis Alliance of Canada.

3. (2014) Arthritis, Ottawa (ON): Statistics Canada. Catalogue No 82-625-X.

4. (2011) Life with arthritis in Canada: A personal and public health challenge. Ottawa (ON): Public Health Agency of Canada.

5. (2015) Connection between mental and physical health [Internet]. Toronto (ON): Canadian Mental Health Association (CMHA).

6. Callahan LF, Ambrose KR (2015) Physical activity and osteoarthritisconsiderations at the population and clinical level. Osteoarthritis and Cartilage 23(1): 31-33.

7. Westby M (2015 ) Exercise and arthritis [Internet]. Atlanta (GA): American College of Rheumatology.

8. Naal FD, Impellizzeri FM, Leunig M (2009) Which is the best activity rating scale for patients undergoing total joint arthroplasty? Clin Orthop Relat Res 467(4): 958-965.

9. Bryan SN, Katzmarzyk PT (2009) Estimating leisure-time physical activity energy expenditure in the Canadian population: A comparison of 2 methods. Appl Physiol Nutr Metab 34(4): 666-672.

10. (2014) Physical activity during leisure time. Ottawa (ON): Statistics Canada.

11. (2011) Canadian Community Health Survey (CCHS). Derived variable (DV) specifications. Ottawa (ON), Statistics Canada.

12. Larson CO. (2002) Use of the SF-12 instrument for measuring the health of homeless persons. Health Services Research 37(3): 733-750.

13. Lacson Jr E, Xu J, Lin SF, Guerra Dean S, Lazarus JM, et al. (2010) A comparison of sf-36 and sf- 12 composite scores and subsequent hospitalization and mortality risks in long-term dialysis patients. Clin J Am Soc Nephrol 5(2): 252-260.

14. (2001) Interpreting the SF-12. Utah Department of Health. Utah Health Status Survey.

15. Hopman WM, Towheed T, Anastassiades T, Tenenhouse A, Poliquin S, et al. (2000) Canadian normative data for the SF-36 health survey. CMAJ 16(3): 265-271.

16. Wewers ME, Lowe NK (1990) A critical review of visual analogue scales in the measurement of clinical phenomena. Research in Nursing and Health 13(4): 227-236.

17. Shuttleworth M (2009) Test-retest reliability. Exploreable.

18. Ainsworth BE, Haskell WL, Herrmann SD, Meckes N, Bassett Jr DR, et al. (2011) Compendium of physical activities: A second update of codes and MET values. Medicine and Science in Sports and Exercise 43(8): 15751581.

19. Waller JL (2012) How to perform and interpret chi-square and t-tests. Augusta (GA): SAS Global Forum 2012.

20. Chmelo E, Nicklas B, Davis C, Miller GD, Legault C, Messier S (2013) Physical activity and physical function in older adults with knee osteoarthritis. Journal of Physical Activity and Health 10(6): 777-783.

21. Cooney JK, Law RJ, Matschke V, Lemmey AB, Moore JP, et al. (2011) Benefits of exercise in rheumatoid arthritis. Journal of Aging Research p. 1-14.

22. Scarvell J, Elkins MR (2011) Aerobic exercise is beneficial for people with rheumatoid arthritis. British Journal of Sports Medicine 45(12): 1008-1009. 
23. Pelland L, Brosseau L, Wells G, MacLeay L, Lambert J, et al. (2004 ) Efficacy of strengthening exercises for osteoarthritis (Part I): A metaanalysis. Physical Therapy Reviews 9(2): 77-108.

24. Breedland I, van Scheppingen C, Leijsma M, Verheij Jansen NP, van Weert E (2011) Effects of a group-based exercise and educational program on physical performance and disease self-managements in rheumatoid arthritis: A randomized controlled study. Physical Therapy 91(6): 879893.

25. Hurkmans E, van der Giesen FJ, Vliet Vlieland TPM, Schoones J, Van den Ende ECHM (2009) Dynamic exercise programs (aerobic capacity and/or muscle strength training) in patients with rheumatoid arthritis. Cochrane Database of Systematic Reviews 7(4).

26. Lin SY, Davey RC, Cochrane T (2004) Community rehabilitation for older adults with osteoarthritis of the lower limb: A controlled clinical trial. Clinical Rehabilitation 18(1): 92-101.

\section{ISSN: 2574-1241}

DOI: 10.26717/BJSTR.2019.13.002416

Wally J Bartfay. Biomed J Sci \& Tech Res

(c) (P) This work is licensed under Creative

Submission Link: https://biomedres.us/submit-manuscript.php
27. Abell JE, Hootman JM, Zack MM, Moriarty D, Helmick CG (2005) Physical activity and health related quality of life among people with arthritis. The Journal of Epidemiology Community Health 59(5): 380-385.

28. Austin S, Qu H, Shewchuk RM (2012) Association between adherence to physical activity guidelines and health-related quality of life among individuals with physician-diagnosed arthritis. Quality of Life Research 21(8): 1347-1357.

29. (2013) Canadian physical activity guidelines. Canadian sedentary behaviour guidelines. Ottawa (ON): Canadian Society for Exercise Physiology (CSEP).

30. Verial D (2017) The effects of a small sample size limitation. Sciencing.

$\begin{array}{ll}\text { BIOMEDICAL } & \text { Assets of Publishing with us } \\ \text { RESEARCHES } & \text { - Global archiving of articles } \\ & \text { - Immediate, unrestricted online access } \\ \end{array}$

